\title{
Alkol-Madde Bağımlılarında D Tipi Kişilik Özellikleri ve Aleksitimi
}

\author{
Filiz ÖZSOY ${ }^{1}$
}

Özet: Biz çalışmamızda; Alkol/madde kullanım bozukluğu (AMKB) tanılı hastaların depresyon-anksiyete skorları, D tipi kişilik özellikleri ve aleksitimi düzeylerini değerlendirmeyi amaçladık. Çalışmaya; 30 alkol (AKB) ve 30 madde (MKB) kullanım bozukluğu tanılı hasta ve 30 kontrol grubu alındı. Tüm katılımcılara; Hastane Anksiyete Depresyon Ölçeği (HADÖ), D tipi kişilik ölçeği (DS-14) ve Toronto Aleksitimi Ölçeği (TAÖ) uygulandı. Hasta grubunda; DS-14 her iki alt boyut kontrol grubuna göre istatistiksel olarak yüksekti $(p<0.001)$. Benzer şekilde HADÖ her iki alt boyut hasta grubunda kontrol grubundan yüksekti $(\mathrm{p}<0.05)$. Son olarak hasta grubunda TAÖ sadece duyguları tanıma alt boyutu anlamlı idi $(\mathrm{p}<0.001)$, diğer alt boyutlarda istatistiksel farklılık tespit edilmedi $(\mathrm{p}>0.05)$. Elde ettiğimiz bulgular 1şığında AMKB tanılı hastaların; daha kaygıll-depresif ve belli alt boyutlarda aleksitimik olduğu ve ek olarak D tipi kişilik özelliklerine sahip oldukları bulundu. Bulgularımızın önem kazanabilmesi için büyük örneklemlerle ileri araştırmalar yapılmalıdır.

Anahtar kelimeler: Alkol kullanım bozukluğu, madde kullanım bozukluğu, D tipi kişlik özellikleri, aleksitimi, anksiyete, depresyon.

\section{Type Personality Traits And Alexithymia in Alcohol-Substance Addicts}

\begin{abstract}
We aimed to evaluate depression-anxiety scores, D-type personality traits and alexithymia levels of patients with alcohol/substance use disorder. Thirty patients with alcohol, 30 substance use disorders and 30 control groups were included in the study. All participants; Hospital Anxiety Depression Scale (HADS), D type personality scale (DS-14), Toronto Alexithymia Scale (TAS) were applied. In the patient group; DS-14 was significantly higher than the control group ( $\mathrm{p}<0.001)$. Similarly, HADS was higher in both subdimensions in the patient group than in the control group $(\mathrm{p}<0.05)$. Finally, only the emotion recognition subscale of TAS was significant in the patient group ( $p$ $<0.001$ ), but no statistical difference was detected in the other sub-dimensions. In the light of our findings; they were more anxious-depressive and alexithymic in certain sub-dimensions and additionally had D-type personality traits. In order for our findings to gain importance, further research should be conducted with large samples.
\end{abstract}

Key words: Alcohol use disorder, substance use disorder, type D personality characteristics, alexithymia, anxiety, depression.

\footnotetext{
${ }^{1}$ Uzm. Dr., Tokat Devlet Hastanesi, Psikiyatri

Address of correspondence/ Yazışma adresi: Uzm. Dr., Filiz Özsoy, Tokat Devlet Hastanesi, Psikiyatri E-mail: flzkoseoglu82@gmail.com
}

Date of Received/Geliş Tarihi: 15.10.2019, Date of Revision/Düzeltme Tarihi: 02.11.2019, Date of Acceptance/Kabul Tarihi: 05.11.2019

Citing/ Referans Gösterimi: Özsoy, F. (2019). Alkol-Madde Bağımlılarında D Tipi Kişilik Özellikleri ve Aleksitimi. Kıbrıs Türk Psikiyatri ve Psikoloji Dergisi, 1(Özel Sayl.1): 12-15 doi:10.35365/ctjpp.19.special1.3 


\section{Giriş}

Alkol/Madde Kullanım Bozukluğu (AMKB); alınan tüm önlemlere rağmen önemli bir halk sağlığı sorunu olmaya devam etmektedir. AMKB olan bireylerin; yenilik arayış1, dürtüsellik gibi bazı kişilik özelliklerinin kontrollerden farklılık gösterdiği tespit edilmiştir (Conway, Kane, Ball, Poling ve Rounsaville, 2003).

"Distressed personality"; D tipi kişilik negatif affektivite (NA) ve sosyal inhibisyonun (SI) birleşmesinden oluşur. NA; depresif duygulanım ile ilişkilendirilmiştir. SI ise; sosyal ortamlarda duygu ve davranışların dışa vurulmasını engelleme eğilimidir. NA puanı yüksek kişiler; endişeli, karamsar, çabuk kızabilen ve düşmanlık yaşamaya eğilimli olarak tanımlanır. SI puanı yüksek olan kişiler ise; hem daha çok engellenmiş, hem de başka insanların yanında engellenmekten korktukları için güvensiz hisseden ve stresli kişilerdir (Denollet, 2015).

Tek başına bir hastalık göstergesi olmayan aleksitimi kavramı; duyguları ayırt etmede ve ifade etmede güçlük, yaratıcı süreçlerde kısıtlılık, kısıtlı empati kurma ve dışsal düşünmede kısıtlılık olarak tanımlanan bir kişilik özelliğidir (Zhang, Wang, Zhu, Li, Zhu, Yu ve et al., 2017). Aleksitimik bireylerin, duygularını ifade etme yolu olarak somatik belirtileri kullanmayı seçtikleri gösterilmiştir (Bailey ve Henry, 2007).

Literatürde; AMKB tanılı hastaların kişilik özelliklerinin irdelendiği çalışmalar bulunmaktadır fakat D tipi kişilik özelliklerinin irdelendiğikısıtlı sayıda çalışma vardır (Şentürk, 2018; Yıldız, 2012). Biz çalışmamızda AMKB tanılı hastaların kişilik özellikleri ve aleksitimi düzeylerini değerlendirmeyi amaçladık.

\section{Yöntem}

Çalışmaya; DSM-V kriterlerine göre 30 alkol (AKB) ve 30 madde (MKB) kullanım bozukluğu tanılı hasta ve 30 kontrol grubu alındı. Hastane Anksiyete ve Depresyon Ölçeği (HADÖ): Depresyon ve anksiyete düzeylerini değerlendiren bir ölçektir. Kesme puanı depresyon için 8; anksiyete için 11 olarak hesaplanmıştır (Zigmond ve Snaith, 1983; Aydemir, 1997). Toronto Aleksitimi Ölçeği (TAÖ20): Dışa-dönük düşünme, duyguları tanımada güçlük ve duyguları ifade etmede güçlük alt olan 20 soruluk bir ölçektir (Bagby, Parker ve Taylor, 1994; Güleç, Köse, Yazıcı-Güleç, Çıtak, Evren ve et al., 2009). Tip D Kişilik Ölçeği (DS-14): Her maddesi 0-4 arasında puanlanan, 14 maddeli, iki alt boyuttan oluşur. Her iki alt boyut için de kesme puanı $\geq 10$ olarak kabul edilir (Denollet, 2015; Alçelik, Yıldırım, Canan, Eroğlu, Aktaş ve Savli, 2012). İstatistiksel Analiz: Nicel değişkenler arasında ilişki olup olmadığı değerlendirilirken; İki Ortalama Arasındaki Farkın Önemlilik testi ve pearson korelasyon katsayısından yararlanılmaktadır.

\section{Bulgular}

30 kişi $\mathrm{AKB}, 30$ kişi $\mathrm{MKB}$ ve 30 kişi de sağlıklı kontrol grubu idi. MKB tanılı hastaların \%4.8'i kadındı. AKB tanılı hastalarda kadın cinsiyette kişi yoktu. Hastaların yaş ortalamas1; $\mathrm{AKB}$ hastalarının $41.13 \pm 10.30, \quad \mathrm{MKB}$ hastalarının ise $28.91 \pm 9.81$ idi. Uygulanan ölçeklerden DS14 negatif duygulanım alt boyutu AKB için 16.43 \pm 6.79 , MKB için $14.93 \pm 7.33$ idi. Sosyal içe çekilme alt boyutu ise AKB için; $13.033 \pm 5.81, \mathrm{MKB}$ için $11.606 \pm 6.06$ idi. Bu iki alt boyut da kontrol grubuna göre istatistiksel olarak anlamlı yüksek olarak hesaplandı (Tüm parametrelerde $\mathrm{p}<0.001)$. HADÖ; depresyon alt boyutu AKB 8.26 \pm 3.75 , $\mathrm{MKB}$ için ise $8.24 \pm 3.83$ olarak bulundu. Anksiyete alt boyutu için AKB $8.73 \pm 3.94$, MKB 9.36 \pm 4.60 idi. Her iki alt boyut da kontrol grubundan yüksek olarak saptand 1 $(\mathrm{p}<0.05)$. TAÖ için ise; duyguları tanıma alt boyutu AKB

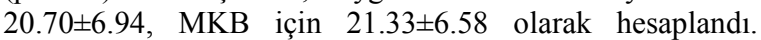
Duyguları ifade etme alt boyutu; AKB 14.93 \pm 3.42 , MKB için 14.81 \pm 3.62 idi. Dışa dönüklük alt boyutu ise $\mathrm{AKB}$ $24.73 \pm 5.13$, MKB hastalarında $25.575 \pm 4.84$ olarak hesaplandı. TAÖ için kontrol grubuna kıyasla sadece duyguları tanıma alt boyutu anlamlı idi $(\mathrm{p}<0.001)$, diğer alt boyutlarda istatistiksel olarak anlamlı bir farklılık tespit edilmedi ( $>00.05)$. AKB ve MKB hastalarının bir biri ile kıyasında ise hiçbir ölçekte anlamlı bir farklılık saptamadık.

\section{Tartışma}

Alkol/madde kullanım bozukluğu tanısı ile tedavi alan pek çok hasta depresif şikayetlerden yakınmaktadır (Keskin ve Gümüş, 2017; Fridrici, Leichsenring-Driessen, Driessen, Wingenfeld, Kremer ve Beblo, 2013). Ek olarak alkol ve madde kullanım bozukluğu olan kişilerde depresif bozukluk ve kaygı bozuklukları görülme olasılığı yüksek olarak bildirilmektedir (Keskin ve Gümüş, 2017). Bizim sonuçlarımızda bu bulgularla uyumlu niteliktedir. Alkol ve madde kullanım bozukluğu tanılı hastaların yapılan görüşmelerde DSM-V depresyon bozuklukları ve kaygı bozuklukları tanı kriterlerini karşılayacak düzeyde semptomları olmasa da depresyon ve kaygı skorları kontrol grubundan yüksek olarak hesaplanmıştır. Alkol ve madde kullanımı ile birlikte depresif bozukluk ya da kaygı bozukluğunun varlığı bağımlılık tedavisini olumsuz olarak etkilemektedir. Literatürdeki çalışmalarda alkol ve madde kullanım bozukluğuna ek gelişen depresyonun hastaneye yatış sıklığını arttırdığı, tedaviye yanıtı geciktirdiği, yeti yitimi gelişme olasılığını arttırdığını göstermiştir (Keskin ve Gümüş, 2017). Bağımlılık tedavi planlamasında depresif ve kaygı semptomları; hastaların işlevsellikleri açısından mutlaka dikkate alınmalıdır.

Bizim sonuçlarımızda hasta grubunun duyguları tanıma alt boyutu kontrol grubundan istatistiksel olarak anlamlı idi. Aleksitimi skalası diğer alt boyutlarda anlamlılık tespit edilmedi. Aleksitimi tek başına psikiyatrik bir hastalığın göstergesi değildir. TAÖ-20 kullanılarak yapılan çalışmalarda; duyguları tanımada güçlük alt boyutu ve internet bağımlılığının ilişkili olduğu gösterilmiştir (Dalbudak, Evren, Aldemir, Çoşkun, Uğurlu ve Yıldırım, 2013; De Berardis, D'Albenzio, Gambi, Sepede, Valchera, Conti ve etal., 2009). Alkol kullanım bozukluğu olan erkek hastalarda yapılan bir çalışmada; hastaların daha aleksitimik oldukları saptanmıştır. Ek olarak aleksitimik olan hastaların daha erken yaşta alkole başladıkları da tespit edilmiştir (Evren, Eken ve Çakmak, 2003). Üniversite öğrencilerinde yapılan bir çalışmada ise; duyguları tanımada güçlük, duyguları söze dökmede güçlük ve dışa dönük düşünmede 
güçlüğün akıllı telefon bağımlılığını yordamada etkili olduğu gösterilmiştir (Özen ve Topçu, 2017).

Psikiyatri hastalarında DS-14 kullanılarak yapılan kısıtlı sayıda çalışma vardır (Şentürk, 2018; Yıldız, 2012; Park, Ko, Lee, Lee, Kim, 2014; Spek, Nefs, Mommersteeg, Speight, Pouwer, Denollet, 2018). DS-14 ölçeği; "negatif affektivite" ve "sosyal inhibisyon" alt boyutlarından oluşmaktadır. "Negatif affektivite"; depresif duygulanım ve "sosyal inhibisyon" ise sosyal ilişkilerdeki çekiniklik ile ilişkilendirilmiştir ((Denollet, 2015; Alçelik, Yıldırım, Canan, Eroğlu, Aktaş ve Savli, 2012). Madde kullanım bozukluğu olan kişiler ile yapılan bir çalışmada; hastaların sağliklı kontrollere göre D tipi özelliklere daha yüksek oranda sahip olduğu görülmüştür (Yıldız, 2012). Başka bir çalıșmada; alkol/ madde kötüye kullanımı olan kişilerde DS-14 her iki alt boyut puanları da kontrol grubundan yüksek olarak bulunmuştur. Aynı çalışmada D tipi kişilik özelliklerine sahip olanların daha depresif ve intihar olasılığı daha yüksek kişiler olduğu tespit edilmiştir
(Şentürk, 2018). Psikiyatri hastaları ve D tipi kişilik özelliklerinin irdelendiği çalışmalarda, D tipi olmanın intihar olasılığını arttırabileceği gösterilmiştir (Park, Ko, Lee, Lee, Kim, 2014). Alkol/madde kullanım bozukluğu olan kişiler ile DS-14 kullanılarak yapılan çalışmalarda hastaların depresyon skorları kontrol grubundan yüksek bulunmuștur (Şentürk, 2018; Y1ldı, 2012). Bizim sonuçlarımızda bu çalışmalarla paralel nitelikte hastaların hem depresyon-kaygı skorları yüksek hem de daha fazla D tipi özellikler gösterdiği görülmüştür. Biz çalışmamızda hastaların özkıyım düşüncelerini sorgulamadığımız için D tipi kişilik özellikleri ve özkıyım arasında ilișki kuramadık. Literatürde D tipi kişilik ilk kardiyak hastalıklar ile ilişkilendirilmiştir. Daha sonra diyabetes mellitus, hipertansiyon gibi hastalıklar ile olan ilişkisi gösterilmiştir (Spek, Nefs, Mommersteeg, Speight, Pouwer, Denollet, 2018; Mols ve Denollet, 2010). Çalışmamıza katılan hastaların ek tıbbi hastalıkları olmadığı için ve D tipi özellikler ile aralarında ilișki kurulamadı.

\section{Kaynaklar}

Alçelik, A., Yildirim, O., Canan, F., Eroglu, M., Aktas, G., \& Savli, H. (2012). A preliminary psychometric evaluation of the type D personality construct in Turkish hemodialysis patients. Journal of Mood Disorders, 2(1), 1.

Aydemir, O. (1997). Hastane anksiyete ve depresyon olcegi Turkce formunun gecerlilik ve guvenilirligi. Turk Psikiyatri Derg., 8, 187-280.

Bagby, R. M., Parker, J. D., \& Taylor, G. J. (1994). The twenty-item Toronto Alexithymia Scale-I. Item selection and cross-validation of the factor structure. Journal of psychosomatic research, 38(1), 23-32.

Bailey, P. E., \& Henry, J. D. (2007). Alexithymia, somatization and negative affect in a community sample. Psychiatry research, 150(1), 13-20.

Conway, K. P., Kane, R. J., Ball, S. A., Poling, J. C., \& Rounsaville, B. J. (2003). Personality, substance of choice, and polysubstance involvement among substance dependent patients. Drug and alcohol dependence, 71(1), 65-75.

Dalbudak, E., Evren, C., Aldemir, S., Coskun, K. S., Ugurlu, H., \& Yildirim, F. G. (2013). Relationship of internet addiction severity with depression, anxiety, and alexithymia, temperament and character in university students. Cyberpsychology, Behavior, and Social Networking, 16(4), 272-278.

De Berardis, D., D'Albenzio, A., Gambi, F., Sepede, G., Valchera, A., Conti, C. M., ... \& Serroni, N. (2009). Alexithymia and its relationships with dissociative experiences and Internet addiction in a nonclinical sample. CyberPsychology \& Behavior, 12(1), 67-69.

Denollet, J. (2005). DS14: standard assessment of negative affectivity, social inhibition, and Type D personality. Psychosomatic medicine, 67(1), 89-97.

Evren, C., Eken, B., \& Cakmak, D. (2003). Alexithymia among alcohol dependent patients and its relationship with depression, anxiety and personality disorders. Journal of Dependence, 4, 47-52.
Fridrici, C., Leichsenring-Driessen, C., Driessen, M., Wingenfeld, K., Kremer, G., \& Beblo, T. (2013). The individualized alcohol Stroop task: No attentional bias toward personalized stimuli in alcoholdependents. Psychology of Addictive Behaviors, 27(1), 62.

Güleç, H., \& Köse, S. (2009). Yazıcı Güleç M, Çıtak S, Evren C, Borckardt J, ve ark. Yirmi soruluk Toronto Aleksimi Ölçeği'nin Türkçe uyarlamasının geçerlik ve güvenirliğinin incelenmesi. J Clin Psychopharmacol, 19(3), 213-219.

Keskin, G., \& Gümüş, A. B. (2017). Alkol ve madde bağımlılarında depresif belirtiler ve depresif belirtilerle ilişkili değişkenlerin incelenmesi. Dusunen Adam,30(2), 124.

Mols, F., \& Denollet, J. (2010). Type D personality among noncardiovascular patient populations: a systematic review. General hospital psychiatry, 32(1), 66-72.

Özen, S., \& Topcu, M. (2017). Tıp fakültesi öğrencilerinde akıllı telefon bağımlılı̆̆1 ile depresyon, obsesyonkompulsiyon, dürtüsellik, aleksitimi arasındaki ilişki. Bağımlılık Dergisi, 18(1), 16-24.

Park, Y. M., Ko, Y. H., Lee, M. S., Lee, H. J., \& Kim, L. (2014). Type-D personality can predict suicidality in patients with major depressive disorder. Psychiatry investigation, 11(3), 232

Spek, V., Nefs, G., Mommersteeg, P. M., Speight, J., Pouwer, F., \& Denollet, J. (2018). Type D personality and social relations in adults with diabetes: results from diabetes MILES-The Netherlands. Psychology \& health, 33(12), 1456-1471.

Şentürk, S. (2018). Alkol veya madde kötüye kullanımı tanısı almış bireyler ile sağlıklı kontrollerin d tipi kişilik yapısına sahip olma açısından karşılaştırılması (Doctoral dissertation, Sosyal Bilimler Enstitüsü). 
Yıldız, A. (2012). Alkol Bağımlılı̆̆ının Tip D Kişilik İle İlişsisinin Değerlendirilmesi. Yayınlanmamış Uzmanlık Tezi, Gazi Üniversitesi, Psikiyatri AD, Ankara.
Zhang, L., Wang, X., Zhu, Y., Li, H., Zhu, C., Yu, F., \& Wang, K. (2017). Selective impairment of decision making under ambiguity in alexithymia. BMC psychiatry, 17(1), 378.

Zigmond, A. S., \& Snaith, R. P. (1983). The hospital anxiety and depression scale. Acta psychiatrica scandinavica, 67(6), 361-370. 